\title{
Residual Stress Relaxation of Thin-walled Long Stringer Made of Aluminum Alloy 7050-T7451 under Transportation Vibration
}

\author{
Yinfei Yang ${ }^{1 *}$, Lu Jin ${ }^{1}$, Jixing Du ${ }^{1}$, Liang $\mathrm{Li}^{1}$ and Wei Yang ${ }^{2}$
}

\begin{abstract}
Thin-walled long stringer made of aluminum alloy 7050-T7451 is prone to deformation during transportation, so a research of residual stress relaxation was launched in this paper. The transport resonance stress of long stringer was analyzed based on the power spectral density of road transport acceleration. The residual stress relaxation experiment of aluminum alloy 7050-T7451 under different equivalent stress levels was designed and carried out. According to the amount of residual stress relaxation in the experiment, an analytical model was established with the equivalent stress level coefficient. The deflection range of long stringer was evaluated under different damping ratios. The results show that when the equivalent stress exceeds $0.8 \sigma_{0.2}$ the residual stress relaxation of the thin-walled samples occurs. The residual stress relaxation increases linearly with the equivalent stress, which is logarithmically related to the loading cycle. The deformation caused by residual stress relaxation of the long stringer is proportional to the square of the length and the bending moment caused by stress rebalance, and inversely proportional to the moment of inertia of the structure. As the damping ratio decreases from 0.03 to 0.01 , the total deflection of the long stringer increases from 0 to above $1.55 \mathrm{~mm}$.
\end{abstract}

Keywords: Aluminum alloy 7050-T7451, Large thin-walled part, Transportation process, Residual stress, Structural deformation

\section{Introduction}

The long stringer is a longitudinal member of the fuselage structure, which is mainly used to bear the axial force caused by the bending of the fuselage. It has high requirements for geometric accuracy and stress status [1-4]. The first few natural frequencies of thin-walled long stringer are within the range of the power spectral density of road transport acceleration. The stringer inevitably resonates during road transportation. When the resonance causes residual stress relaxation or the combined stress of vibration stress and initial stress exceeds the yield strength, the stringer will be deformed. This leads to assembly difficulties and impairs service performance [5-9].

\footnotetext{
*Correspondence: yangyf@nuaa.edu.cn

${ }^{1}$ Nanjing University of Aeronautics and Astronautics, Nanjing 210016,

China

Full list of author information is available at the end of the article
}

Many scholars studied the residual stress relaxation problems under cyclic loading such as vibratory stress relief and fatigue [10-17]. It has been found that the rate of residual stress relaxation can be drastic in the first few cycles due to the static effect. In the subsequent cyclic loading, the residual stress gradually relaxes. The amount of residual stress relaxation is logarithmically related to the loading cycle. Kodama measured the residual stress relaxation on the surface of shot peened specimens by X-ray diffraction [18]. Experimental data indicates that the residual stress decreases linearly with the loading cycle. Based on the applied stress amplitude and the loading cycle, a concise linear logarithmic analytical model was proposed. Han studied the redistribution of the residual stress around the weld of welded steel members by the applied load [19]. Under cyclic loading, the residual stress is greatly relaxed in the early cycles, and then gradually relaxes 
with the increase of the loading cycle. An analytical model was established based on the linear relaxation of the residual stress to quantitatively predict the residual stress relaxation. Zhuang et al. [20] used the finite element analysis method to simulate the relaxation of surface residual stress according to the Bauschinger effect, and established an analytical model of the residual stress relaxation. The parameters of the model include the magnitude and distribution of residual stress, the cold working, the applied stress and the loading cycle.

Residual stress relaxation causes the deformation of parts [21]. The relationship between residual stress and deformation can be studied through experiments or finite element simulations [22-24]. Meng et al. proposed a method to measure the equivalent residual stress and depths of the affected layers [25]. The corresponding deformations caused by the milling induced residual stress can be predicted in workpieces with different rigidities. Huang studied the principal influence factors on the monolithic component deformation by finite element simulations and experiments [26]. The result shows that the deformation caused by the blank initial residual stress accounted for $90 \%$ of the total deformation of the component. Masoudi et al. studied the relationship between residual stress and deformation under different processing conditions by doing turning experiments on 7075-T6 aluminum alloy thin-walled cylinders [27]. The deformation of the thin-walled cylinder increases with the increase of the cutting force and the cutting heat.

The material residual stress relaxation model under complex loading conditions and the residual stress relaxation spatial distribution model on complex structures are essential foundations for evaluating the transportation deformation of structural parts of aviation. In the case of transport resonance, the vibration frequency range is vast, and the distribution of the resonance region is complicated. The vibration cycles and the vibration stress values of each position are greatly different, so the residual stress relaxation at each position and the resulted deformation are also large. In this paper, the vibration modes of long stringer made of aluminum alloy 7050-T7451 during transportation were studied. The spatial distribution model of residual stress relaxation was constructed. The deflection of the long stringer was evaluated under typical transportation conditions.

\section{Experimental Details}

\subsection{Random Response Analysis of the Long Stringer}

The geometric size of the long stringer is $5000 \mathrm{~mm} \times 200 \mathrm{~mm} \times 50 \mathrm{~mm}$, and the wall thickness is
Table 1 Material parameters of aluminum alloy 7050T7451

\begin{tabular}{llll}
\hline Density $\left(\mathbf{g} / \mathrm{cm}^{\mathbf{3}}\right)$ & $\begin{array}{l}\text { Young's } \\
\text { modulus (GPa) }\end{array}$ & Poisson's ratio & $\begin{array}{l}\text { Yield strength } \\
(\mathbf{M P a})\end{array}$ \\
\hline 2.83 & 70.3 & 0.33 & 449 \\
\hline
\end{tabular}

$1.5 \mathrm{~mm}$. The material parameters are shown in Table 1 . The constraints of the long stringer during the plant turnover are $A B$ and $C D$ hinges, as shown in Figure 1. PSD curves refer to ASTM D4728-06 for power spectral density of highway transportation acceleration in Table 2 [28], the vibration stress and displacement of the long stringer during road transportation were simulated and analyzed.

The damping ratio of aluminum alloy is generally between 0.01 and 0.03 . The random response analysis of the long stringer was simulated under different damping ratios using ABAQUS. As shown in Table 3, the first 21 natural frequencies of the long stringer are all within $0-200 \mathrm{~Hz}$. The first natural frequency of the long stringer is $9.04 \mathrm{~Hz}$. The maximum values of vibration stress $\sigma_{x}$ and displacement $U_{z}$ of the long stringer occurs in the first mode, so they are the research objects in this paper. Taking the damping ratio of 0.012 as an example, $\sigma_{x}$ and $U_{z}$ of the first mode of the long stringer are shown in the Figure 2. The high residual stress region and the high displacement region in the long stringer are at the top of the middle sidewall. $\sigma_{x \max }$ and $U_{z \max }$ of the first mode of the long stringer under different damping ratios are shown in Table 4.

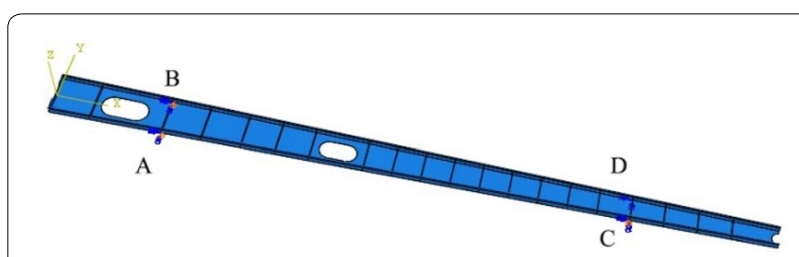

Figure 1 Long stringer's model and boundary conditions

Table 2 PSD of road transport acceleration

\begin{tabular}{ll}
\hline Frequency $(\mathbf{H z})$ & PSD $\left(\mathbf{g}^{\mathbf{2} / \mathbf{H z})}\right.$ \\
\hline 1 & 0.00005 \\
4 & 0.01 \\
16 & 0.01 \\
40 & 0.001 \\
80 & 0.001 \\
200 & 0.00001 \\
\hline
\end{tabular}




\begin{tabular}{|c|c|c|c|}
\hline Mode & $\begin{array}{l}\text { Natural frequency } \\
(\mathrm{Hz})\end{array}$ & Mode & $\begin{array}{l}\text { Natural } \\
\text { frequency } \\
(\mathrm{Hz})\end{array}$ \\
\hline 1 & 9.0427 & 12 & 123.90 \\
\hline 2 & 13.500 & 13 & 150.95 \\
\hline 3 & 23.477 & 14 & 151.06 \\
\hline 4 & 28.905 & 15 & 154.78 \\
\hline 5 & 34.254 & 16 & 156.76 \\
\hline 6 & 39.065 & 17 & 171.93 \\
\hline 7 & 57.782 & 18 & 175.68 \\
\hline 8 & 61.190 & 19 & 178.29 \\
\hline 9 & 64.263 & 20 & 189.55 \\
\hline 10 & 103.59 & 21 & 199.43 \\
\hline 11 & 113.03 & 22 & 204.29 \\
\hline
\end{tabular}

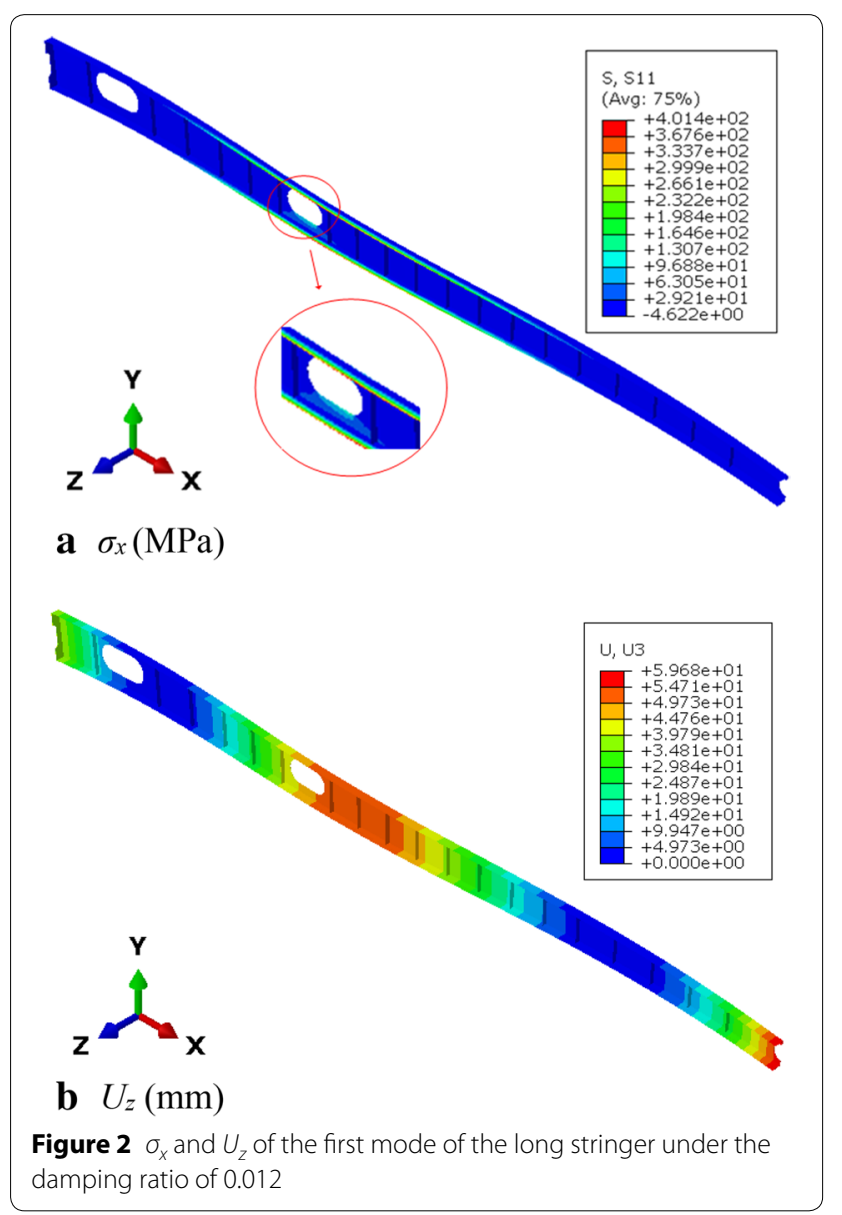

Table $4 \sigma_{x \max }$ and $U_{z \max }$ of the first mode of the long stringer under different damping ratios

\begin{tabular}{lll}
\hline Damping ratio & $\boldsymbol{\sigma}_{\boldsymbol{x} \max }(\mathrm{MPa})$ & $\boldsymbol{U}_{\boldsymbol{z} \max }(\mathbf{m m})$ \\
\hline 0.01 & 578.0 & 85.9 \\
0.012 & 401.4 & 59.7 \\
0.014 & 294.9 & 43.9 \\
0.016 & 225.8 & 33.6 \\
0.018 & 178.4 & 26.5 \\
0.02 & 144.5 & 21.5 \\
0.03 & 64.3 & 9.5 \\
\hline
\end{tabular}

As shown in Table $4, \sigma_{x \max }$ decreases with the increase of the damping ratio. Under different damping ratios, the equivalent stress of resonance stress and initial residual stress may lead to three cases:

(1) The equivalent stress is low and the material does not undergo irreversible changes;

(2) The equivalent stress exceeds the yield strength of the material and the material will plastically deform;

(3) Several cycles of the equivalent stress within a certain range causes local residual stress relaxation. And the rebalance stress leads to deformation of the part.

In order to grasp the local residual stress relaxation law in the case of (3), the cyclic loading experiment of aluminum alloy 7050-T7451 samples under different loading stress levels was carried out, and the residual stress relaxation was observed by residual stress tester.

\subsection{Sample Preparation and Selection}

Aluminum alloy 7050-T7451 is a typical solution strengthening wrought aluminum alloy. After heat treatment and pre-stretching, the internal stress is within $\pm 20 \mathrm{MPa}$ [29]. For the milled parts, the stress of the deformation layer is much larger than the internal stress, and stress relaxation is prone to occur. The stress relaxation in the longitudinal direction of the long stringer is the main cause of the deflection. Therefore, this paper simplified the stress of the deformation layer into the two-dimensional residual stress and discussed the effect of the stress relaxation in the longitudinal direction on the deflection of the long stringer.

The size of the sample is designed according to the standard of tensile testing. The sample is clamped with a vise and 2 spacers, as shown in Figure 3. The sample was milled using a milling tool under emulsion cooling conditions. The milling tool's diameter is $12 \mathrm{~mm}$ with 2 blades. The blade length is $45 \mathrm{~mm}$. Milling parameters 


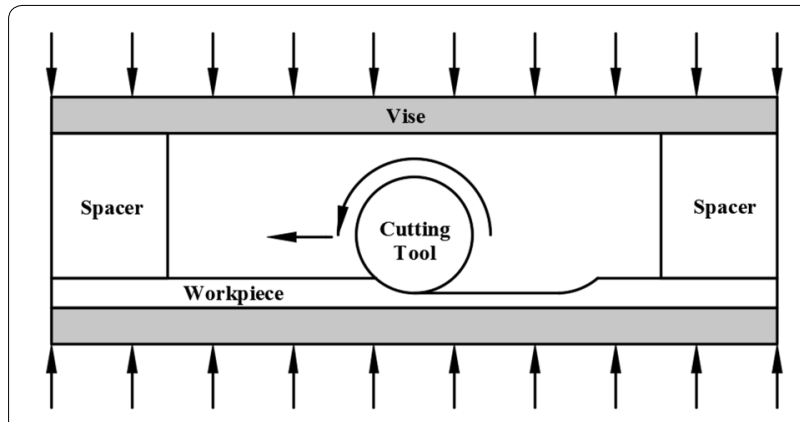

Figure 3 Sample milling setup

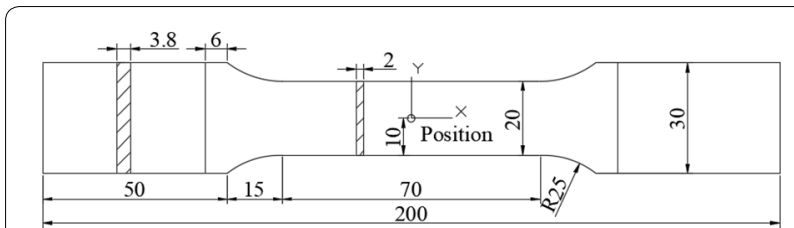

Figure 4 Residual stress measurement point position (unit: $\mathrm{mm}$ )

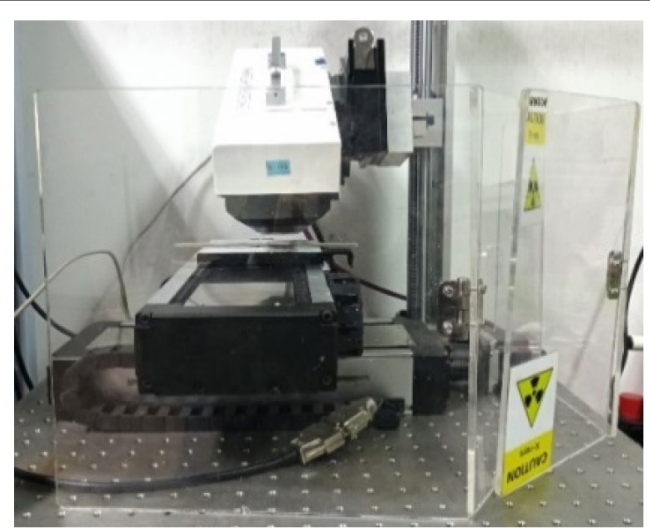

Figure $5 \mu-X 360$ X-ray diffractometer

are: $n=4000 \mathrm{r} / \mathrm{min}, f=4000 \mathrm{~mm} / \mathrm{min}, a_{p}=30 \mathrm{~mm}$. First roughing $a_{e 1}=0.8 \mathrm{~mm}$, then finishing $a_{e 2}=1 \mathrm{~mm}$. A total of 18 samples were made. The residual stress was measured with the $\mu$-X360 X-ray diffractometer at the center point of the sample surface shown in Figure 4. The $\mu$-X360 X-ray diffractometer is shown in Figure 5. Five samples with good stress amplitude consistency were selected for subsequent experiments and analysis. Their residual stress values are shown in Table 5 .

\subsection{Cyclic Loading Experiment Parameters}

In general, when the equivalent stress is lower than the cyclic elastic limit, the residual stress does not change.
Table 5 Sample 1-5 surface residual stress

\begin{tabular}{lllll}
\hline Sample number & $\boldsymbol{\sigma}_{\boldsymbol{x}}(\mathrm{MPa})$ & $\begin{array}{l}\text { Stand } \\
\text { deviation } \\
(\mathbf{M P a})\end{array}$ & $\boldsymbol{\sigma}_{\boldsymbol{y}}(\mathrm{MPa})$ & $\begin{array}{l}\text { Stand } \\
\text { deviation } \\
(\mathbf{M P a})\end{array}$ \\
\hline 1 & 198 & 32 & 190 & 16 \\
2 & 206 & 25 & 188 & 18 \\
3 & 194 & 18 & 206 & 34 \\
4 & 189 & 23 & 205 & 12 \\
5 & 197 & 18 & 189 & 14 \\
Mean value & 196.8 & 23.2 & 195.6 & 18.8 \\
\hline
\end{tabular}

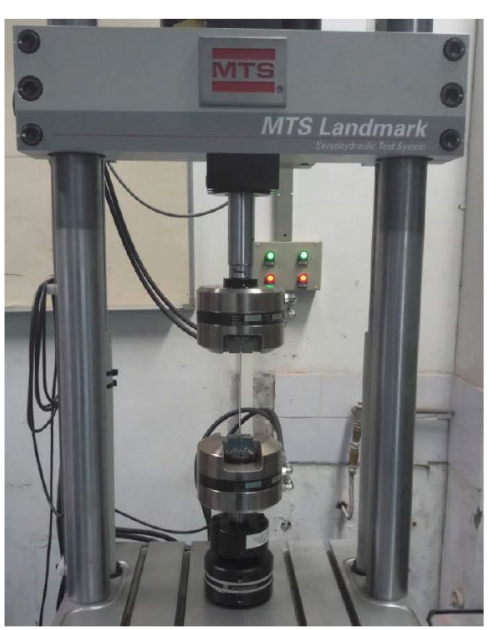

Figure 6 MTS stretching machine

The cyclic elastic limit is considered to be $0.8 \sigma_{0.2}[30,31]$. Therefore, the equivalent stress levels were set at around $0.8 \sigma_{0.2}$, which were $0.65 \sigma_{0.2}, 0.75 \sigma_{0.2}, 0.85 \sigma_{0.2}$, and $0.95 \sigma_{0.2}$. The residual stress in the depth direction was ignored so that the residual stress in the $Z$-direction $\sigma_{z}$ was considered to be 0 . The experiment was based on the distortion energy density theory (the fourth strength theory) and the Mises yield criterion to determine the loading stress [32-34], the loading stress was calculated in the $X$-direction at different equivalent stress levels as in Eq. (1):

$$
K \sigma_{0.2}=\sqrt{\left(\sigma_{x s u f}+\sigma_{L K}\right)^{2}+\sigma_{y s u f}^{2}-\left(\sigma_{x s u f}+\sigma_{L K}\right) \sigma_{y s u f}},
$$

where $K$ is the equivalent stress level coefficient, which is 0.65 or 0.75 or 0.85 or 0.95 , respectively; $\sigma_{0.2}$ is the nominal yield strength; $\sigma_{x s u f}$ is the surface stress in the $X$-direction of the sample; $\sigma_{y s u f}$ is the surface stress in the $Y$-direction of the sample; $\sigma_{L K}$ is loading stress in the $X$-direction. 
Table 6 Cyclic loading stress parameters

\begin{tabular}{|c|c|c|c|c|c|}
\hline Initial residual stress (MPa) & Sample number & $\begin{array}{l}\text { Equivalent stress } \\
\text { level }\end{array}$ & Loading stress (MPa) & $\begin{array}{l}\text { Loading force peak } \\
\text { (N) }\end{array}$ & $\begin{array}{l}\text { Loading } \\
\text { force valley } \\
\text { (N) }\end{array}$ \\
\hline \multirow{5}{*}{$\begin{array}{l}\sigma_{x s u f}=196.8 \\
\sigma_{y s u f}=195.6\end{array}$} & 1 & $0.65 \sigma_{0.2}$ & 139 & 5560 & 556 \\
\hline & 2 & $0.75 \sigma_{0.2}$ & 192 & 7680 & 768 \\
\hline & 3 & $0.85 \sigma_{0.2}$ & 243 & 9720 & 972 \\
\hline & 4 & $0.95 \sigma_{0.2}$ & 292 & 11680 & 1168 \\
\hline & 5 & - & - & - & - \\
\hline
\end{tabular}

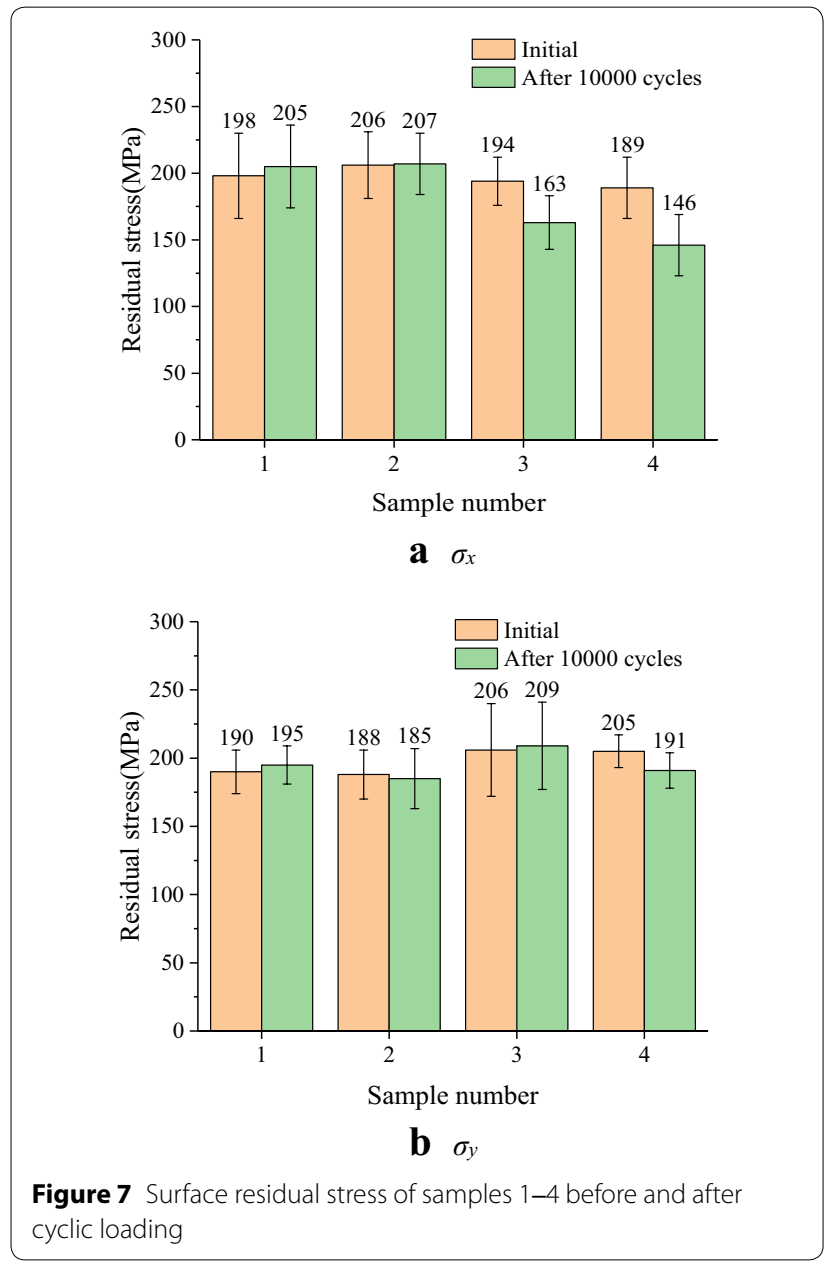

The cyclic loading experiment waveform is a sine wave with a frequency of $10 \mathrm{~Hz}$. In order to avoid buckling of the samples under compressive stress, only the pulling force was applied in this experiment by the MTS stretching machine, as shown in Figure 6. The stress cycle characteristic $r$ is 0.1 . According to Eq. (1), the cyclic loading experiment parameters are shown in
Table 6. After 10000 cycles, the residual stress on the surface of the samples was measured.

\section{Results and Discussion}

\subsection{Residual Stress on the Surface of the Sample after Cyclic Loading}

The residual stress on the surface of the samples 1-4 before and after cyclic loading is shown in Figure 7.

As can be seen from Figure 7, the $\sigma_{x}$ of the samples 1 and 2 slightly increased after cyclic loading for 10000 periods. When the equivalent stress exceeds $0.8 \sigma_{0.2}$, the $\sigma_{x}$ of the sample 3 decreases by $31 \mathrm{MPa}$, and the $\sigma_{x}$ of the sample 4 decreases by $43 \mathrm{MPa}$. The fluctuations of the $\sigma_{y}$ of the samples 1,2 , and 3 are all within $5 \mathrm{MPa}$, and the surface $\sigma_{y}$ of the sample 4 decreases by $14 \mathrm{MPa}$. Since the measurement error of the instrument does not exceed $20 \mathrm{MPa}$, it can be considered that the $\sigma_{x}$ of the samples 3 and 4 exhibits significant residual stress relaxation. It can be seen that when the equivalent stress is between $0.8 \sigma_{0.2}-1.0 \sigma_{0.2}$, the residual stress is relaxed after cyclic loading. Therefore, the cyclic elastic limit of the aluminum alloy $7050-\mathrm{T} 7451$ is about $0.8 \sigma_{0.2}$. When the equivalent stress is larger than $0.8 \sigma_{0.2}$, the residual stress relaxation and the stress redistribution occur after cyclic loading.

The material at the center point of the sample surface was removed by electropolishing, and the residual stress in the depth direction was measured. Using the unloaded sample 5 as a reference, the residual stress changes in the depth direction of the 5 samples are shown in Figure 8.

As can be seen from Figure 8, the peak of the residual stress $\sigma_{x}$ appears at $7.42 \mu \mathrm{m}$ below the machined surface, and the peak of the cutting residual stress $\sigma_{y}$ appears on the machined surface. When the depth is about $40 \mu \mathrm{m}$, the values of $\sigma_{x}$ and $\sigma_{y}$ are both close to 0 . The $\sigma_{x}$ peaks $(7.42 \mu \mathrm{m})$ of samples $1-4$ after cyclic loading were reduced by $17 \mathrm{MPa}, 45 \mathrm{MPa}, 67 \mathrm{MPa}$, and $90 \mathrm{MPa}$, respectively. The peak equivalent stress levels of samples 1-4 were calculated based on the peak residual stress of Sample 5, as shown in Table 7. The results show that the peak equivalent stress of samples $1-4$ is not less than $0.8 \sigma_{0.2}$. The decrease of residual 


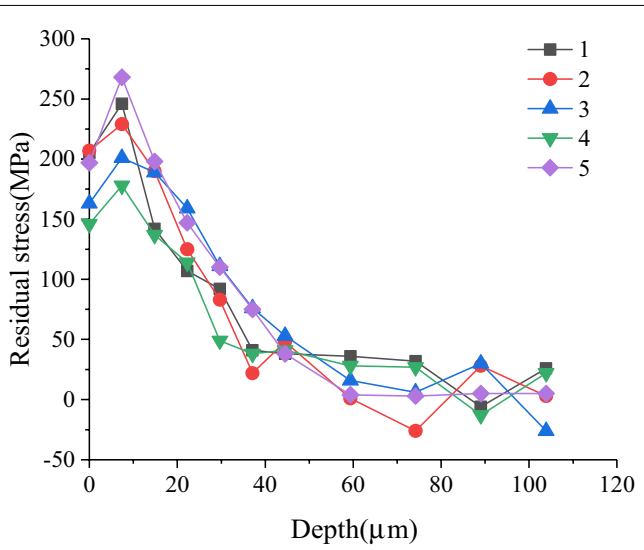

a $\sigma_{x}$

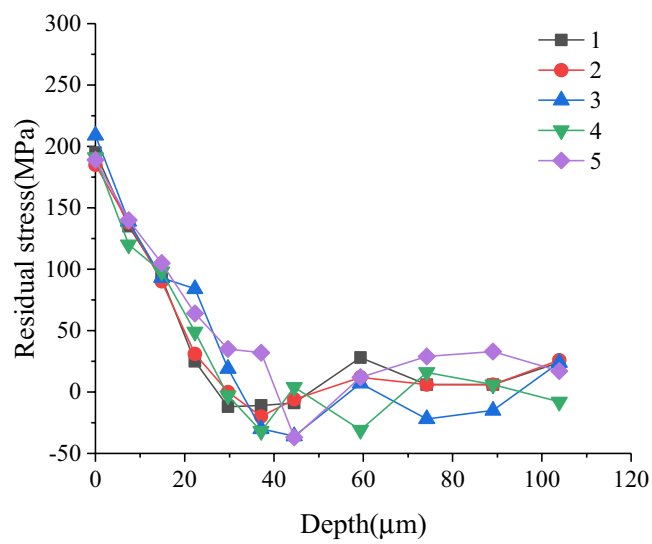

b $\sigma_{y}$

Figure 8 Residual stress along the depth direction of samples 1-5

Table 7 Surface and peak equivalent stress level

\begin{tabular}{lll}
\hline Sample number & $\begin{array}{l}\text { Surface equivalent stress } \\
\text { level }\end{array}$ & $\begin{array}{l}\text { Peak } \\
\text { equivalent } \\
\text { stress level }\end{array}$ \\
\hline 1 & $0.65 \sigma_{0.2}$ & $0.80 \sigma_{0.2}$ \\
2 & $0.75 \sigma_{0.2}$ & $0.91 \sigma_{0.2}$ \\
3 & $0.85 \sigma_{0.2}$ & $1.02 \sigma_{0.2}$ \\
4 & $0.95 \sigma_{0.2}$ & $1.12 \sigma_{0.2}$ \\
5 & - & - \\
\hline
\end{tabular}

stress peak is mainly due to residual stress relaxation and plastic deformation, and the reduction amplitude increases with the equivalent stress.

\subsection{Residual Stress Relaxation Analytical Model of Aluminum Alloy 7050-T7451}

Kodama measured the reduction of residual stress on the surface of shot-peened specimens by X-ray diffraction method and proposed a linear logarithm model [9]. However, the experimental data only supports the phenomenon that the residual stress decreases linearly with the loading cycle, and it is impossible to predict a large amount of relaxation of the stress in the first cycle. Therefore, combined with the previous experiment results, the equivalent stress coefficient $K$ and the cyclic elastic limit $0.8 \sigma_{0.2}$ are used to characterize the relaxation of the $X$-direction residual stress in the first cycle. The logarithmic model of Kodama is modified to obtain an analytical model of residual stress relaxation of aluminum alloy 7050-T7451, as shown in Eqs. (2) and (3):

$$
\begin{aligned}
& \sigma_{r e}^{N}=A+m \lg N, \\
& A=n(K-0.8) \sigma_{0.2}, K \geq 0.8,
\end{aligned}
$$

where $N$ is the number of cycles; $\sigma_{\mathrm{re}}^{\mathrm{N}}$ is the value of the residual stress relaxation after $N$ cycles; the coefficient $\mathrm{m}$ depends on the material; $A$ is the value of the first loading residual stress relaxation; $K$ is the equivalent stress level coefficient; $\sigma_{0.2}$ is the nominal yield strength; the coefficient $\mathrm{n}$ is the correction factor.

According to the experiment results, the values of $X$-direction residual stress relaxation after 10000 cycles of loading were obtained. The over-determined equation was solved by using the data of the residual stress relaxation at the surface and the peak. The residual stress relaxation values exceeding $20 \mathrm{MPa}$ were selected to establish an analytical model. The specific data is shown in Table 8.

\begin{tabular}{|c|c|c|c|c|c|c|}
\hline Group & Depth $(\mu \mathrm{m})$ & Sample number & $N$ & $\sigma_{0.2}(\mathrm{MPa})$ & $\sigma_{r e}^{10000}(\mathrm{MPa})$ & $K$ \\
\hline a & 0 (Surface) & 3 & 10000 & 449 & 31 & 0.85 \\
\hline$b$ & 0 (Surface) & 4 & & & 43 & 0.95 \\
\hline c & 7.42 (Peak) & 2 & & & 39 & 0.91 \\
\hline d & 7.42 (Peak) & 3 & & & 67 & 1.02 \\
\hline e & 7.42 (Peak) & 4 & & & 90 & 1.12 \\
\hline
\end{tabular}

Table 8 Residual stress relaxation values 


\begin{tabular}{|c|c|c|c|}
\hline Group & $\sigma_{r e}^{10000}(\mathrm{MPa})$ & $\sigma_{a n}^{10000}(\mathrm{MPa})$ & Error (\%) \\
\hline a & 31 & 27 & -12.90 \\
\hline b & 43 & 49 & 13.95 \\
\hline c & 39 & 40 & 2.56 \\
\hline$d$ & 67 & 65 & -2.99 \\
\hline e & 90 & 88 & -2.22 \\
\hline
\end{tabular}

According to the five groups of data, the least squares solutions of $\mathrm{m}$ and $\mathrm{n}$ were respectively 3.78 and 0.51 , and the analytical model is shown in Eq. (4):

$$
\sigma_{r e}^{N}=0.51(K-0.8) \sigma_{0.2}+3.78 \lg N .
$$

In summary, the magnitude of residual stress relaxation is mainly related to the magnitude of the equivalent stress and the loading cycle. The higher the equivalent stress is, the greater the residual stress relaxation is at the first cycle. The larger the loading cycle is, the greater the residual stress relaxation is. According to the analytical model Eq. (4), the residual stress relaxation values of the five groups under 10000 cycles of loading were calculated. The errors were calculated by comparing the analytical results $\left(\sigma_{a n}^{10000}\right)$ with the experimental results $\left(\sigma_{r e}^{10000}\right)$, which are shown in Table 9.

It can be seen from Table 9 that the errors of the analytical model are within $15 \%$, which can accurately quantify the relaxation of residual stress and characterize the evolution of residual stress relaxation.

\section{Transport Deformation Assessment of the Long Stringer}

According to the random response analysis results, the high residual stress region in the long stringer is at the top of the middle sidewall. It can be considered as an applied stress. The residual stress relaxation is caused by the equivalent stress. This paper calculated the deformation

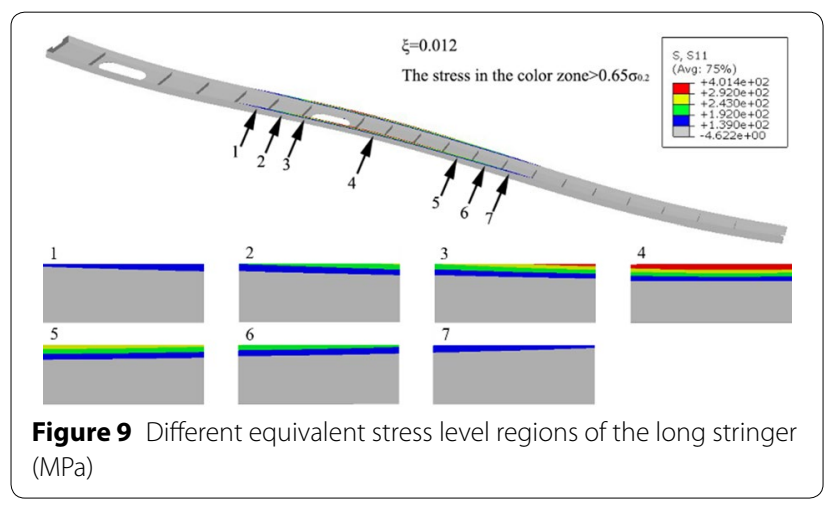

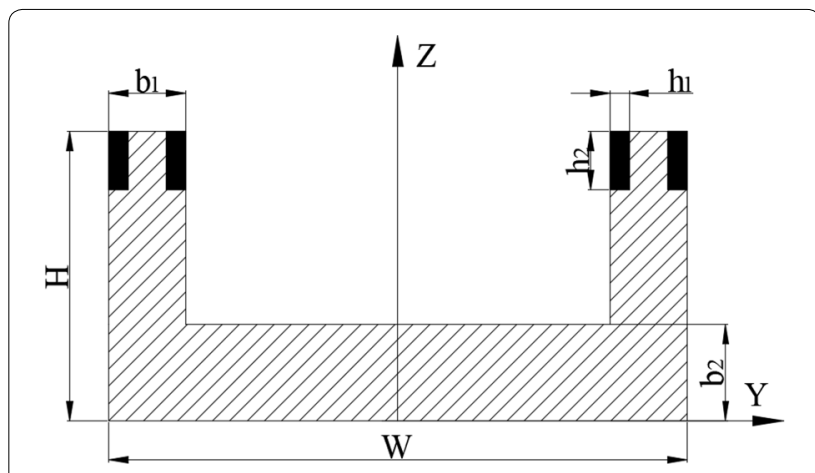

Figure 10 Schematic cross section

of the part caused by the residual stress relaxation of the surface layer. According to Table 4, Table 6 and Table 7, when the damping ratio is less than 0.016 , the part undergoes plastic deformation and residual stress relaxation; between 0.016 and 0.02 , the stress is relaxed; if it is greater than 0.02 , there is no change. Taking the damping ratio of 0.012 as an example, the equivalent stress levels which are greater than $0.65 \sigma_{0.2}$ are the regions of red, yellow, green and blue. The regions 1-7 correspond to different levels of residual stress relaxation regions, as shown in Figure 9. According to the location and size of the residual stress relaxation, the bending deformation of the long stringer under random vibration was calculated. In order to facilitate the calculation, the model was simplified, and the ribs in the long stringer were ignored. A schematic cross section is shown in Figure 10.

The calculation results of the centroid $\left(z_{c}\right)$ and the moment of inertia $\left(I_{y}\right)$ of the part are shown in Eqs. (5) and (6), respectively. The deflection and the end section angle are calculated according to the deflection curve equation:

$$
\begin{aligned}
z_{c} & =\frac{2 b_{1} H^{2}+\left(W-2 b_{1}\right) b_{2}^{2}}{4 b_{1} H+2\left(W-2 b_{1}\right) b_{2}} \\
I_{y} & =\frac{W z_{c}^{3}+\left(W-2 b_{1}\right)\left(b_{2}-z_{c}\right)^{3}+2 b_{1}\left(H-z_{c}\right)^{3}}{3}, \\
M & =\int_{H-h_{2}}^{H} \int_{0}^{h_{1}} 4 \sigma_{r e}^{N}(h)\left(z-z_{c}\right) \mathrm{d} h \mathrm{~d} z \\
\omega & = \begin{cases}\frac{M L^{2}}{8 E I_{y}}, & (\text { region } 4), \\
\frac{M L^{2}}{2 E I_{y}}, & (\text { regions } 1-3,5-7)\end{cases}
\end{aligned}
$$




$$
\theta= \begin{cases}\frac{M L}{2 E I_{y}}, & (\text { region } 4), \\ \frac{M L}{E I_{y}}, & (\text { regions } 1-3,5-7),\end{cases}
$$

where $H$ is the height of the part; $W$ is the width of the part; $b_{1}$ is the thickness of the side wall; $b_{2}$ is the thickness of the web; $h_{1}$ is the depth of the residual stress relaxation region; $h_{2}$ is the height of the residual stress relaxation region; $M$ is the bending moment due to residual stress relaxation; $\sigma_{r e}^{N}(h)$ is the function of the residual stress relaxation in depth; $z$ is the height of the residual stress relaxation region from the $Y$ axis; $\omega$ is the deflection of the residual stress relaxation region; $L$ is the length of the residual stress relaxation region; $E$ is Young's modulus; $\theta$ is the end section angle of the residual stress relaxation region.

According to the residual stress distribution model of the long stringer, the stress distribution region was simplified to be symmetrical at both ends. The maximum deflection of the long stringer is divided into two parts: the deflection of the different regions and the deflection caused by the angle of the end section. The schematic diagram of the total deflection of the long stringer is shown in Figure 11, and the calculation formula is shown in Eq. (10):

$$
\omega_{\max } \approx \sum_{i=1}^{4} \omega_{i}+\sum_{i=1}^{4} L_{i} \tan \theta_{i} \approx \sum_{i=1}^{4} \omega_{i}+\sum_{i=1}^{4} L_{i} \theta_{i}
$$

where $\omega_{\max }$ is the maximum deflection of the part; $\omega_{i}$ is the deflection of different regions; $\theta_{i}$ is the end section angle of different regions; $L_{i}$ is the length from the end section of different regions to one side.

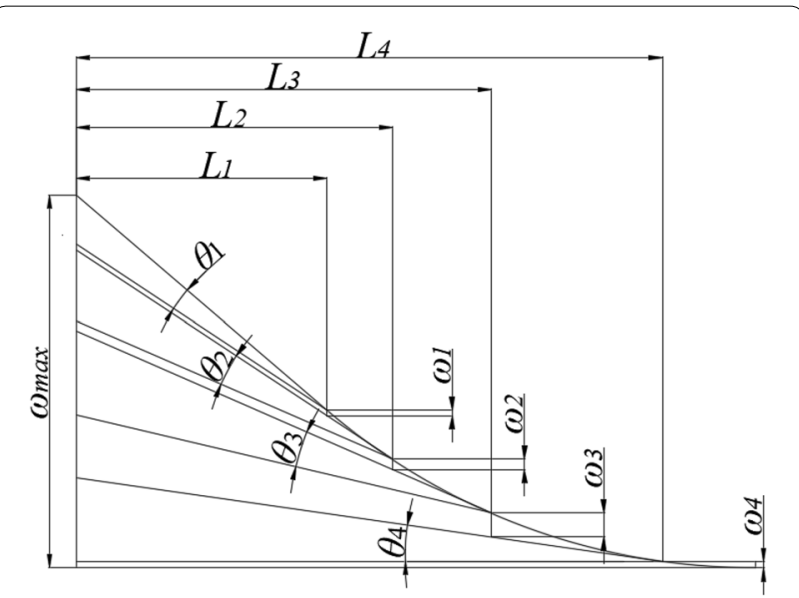

Figure 11 Schematic diagram of the total deflection of the long stringer
The actual size of the long stringer is: $H=50 \mathrm{~mm}$, $W=200 \mathrm{~mm}, b_{1}=1.5 \mathrm{~mm}, b_{2}=1.5 \mathrm{~mm}$. Since the residual stress value is close to 0 at the depth of about $40 \mu \mathrm{m}$, the subsequent residual stress value fluctuates around 0 , so it is considered that $h_{1}=0.04 \mathrm{~mm} . \int_{0}^{0.04} \sigma_{r e}^{N}(h) \mathrm{d} h$ was calculated from the difference between the stress curve of the sample 5 and the stress curve of the samples $1-4 . M$ is the sum of the bending moments generated by the residual stress relaxation in different residual stress relaxation regions. The calculation formula is shown in Eq. (11):

$$
M_{i}=M_{i}^{0.65}+M_{i}^{0.75}+M_{i}^{0.85}+M_{i}^{0.95} .
$$

The subscript $i$ indicates the different residual stress relaxation regions; $M_{i}$ is the bending moment of different residual stress relaxation regions; $M_{i}^{0.65}, M_{i}^{0.75}, M_{i}^{0.85}$ and $M_{i}^{0.95}$ are the bending moments of the different equivalent stress level at different positions of the same residual stress relaxation region.

The result was approximately calculated based on the data of the simulation results. The ABAQUS query function was used to obtain the height values of $M_{i}^{0.65}, M_{i}^{0.75}, M_{i}^{0.85}$ and $M_{i}^{0.95}$ and the length values of Li. According to Eqs. (5)-(11), deflections of the long stringer under different damping ratios were calculated. The results are shown in Table 10.

It can be seen from Table 10 that under different damping ratios, the deflection of the long stringer is varied by the transport resonance stress, and the deflection decreases as the damping ratio increases. It is obvious from Eq. (8) that the deflection of the part due to residual stress relaxation is proportional to the bending moment of the stress rebalance and the square of the length of the part, and inversely proportional to the moment of inertia of the part structure. As the damping ratio decreases from 0.03 to 0.01 , the total deflection of the long stringer increases from 0 to above $1.55 \mathrm{~mm}$. When the long stringer is under severe transportation conditions, the

Table 10 Deflections of the long stringer under different damping ratios

\begin{tabular}{lll}
\hline Damping ratios & Status & $\boldsymbol{\omega}_{\max }(\mathbf{m m})$ \\
\hline 0.01 & $\begin{array}{l}\text { Residual stress relaxation + plastic } \\
\text { deformation }\end{array}$ & 1.55 \\
0.012 & $\begin{array}{l}\text { Residual stress relaxation + plastic } \\
\text { deformation }\end{array}$ & 0.85 \\
0.014 & $\begin{array}{l}\text { Residual stress relaxation + plastic } \\
\text { deformation }\end{array}$ & 0.34 \\
0.016 & Residual stress relaxation & 0.12 \\
0.018 & Residual stress relaxation & 0.02 \\
0.02 & No change & 0 \\
0.03 & No change & 0 \\
\hline
\end{tabular}


residual stress relaxation will occur, which results in deformation. Therefore, the deformation of large thinwalled parts during transportation vibration should be prevented.

\section{Conclusions}

In this paper, random response analysis of the long stringer under transportation vibration was carried out. The residual stress evolution law of aluminum alloy 7050T7451 under 10000 cycles of different equivalent stress levels was studied. The residual stress relaxation was quantified and a reasonable analytical model was established. The deflection of the long stringer was evaluated. The conclusions below have been arrived at:

(1) Resonance occurs in the transportation of long stringer made of aluminum alloy 7050-T7451. The resonance stress is the largest at the first natural frequency, which is prone to causing deformation. The resonance stress decreases with the increase of the damping ratio.

(2) When the equivalent stress exceeds $0.8 \sigma_{0.2}$, the stress of the samples begins to relax. The amount of residual stress relaxation increases with the equivalent stress, which is linearly logarithmically related to the loading cycle. Based on the traditional logarithmic model, an analytical model related to the equivalent stress coefficient and the cyclic elastic limit is proposed. Compared with the experimental results, the errors are within $15 \%$.

(3) The residual stress relaxation of the surface layer caused the deformation of the long stringer. The deflection of the part due to residual stress relaxation is proportional to the bending moment of the stress rebalance and the square of the length of the part, and inversely proportional to the moment of inertia of the part structure. As the damping ratio decreases from 0.03 to 0.01 , the total deflection of the long stringer increases from 0 to above $1.55 \mathrm{~mm}$

\section{Acknowledgements}

The authors sincerely thank to Xuming Niu and Xihui Chen of College of Energy and Power for their critical discussion and reading during manuscript preparation.

\section{Authors' Contributions}

$L J$ and JD were in charge of the whole trial; $L J$ wrote the manuscript; YY, LL and WY assisted with sampling and laboratory analyses. All authors read and approved the final manuscript.

\section{Authors' Information}

Yinfei Yang, born in 1982, is currently the associate professor at College of Mechanical and Electrical Engineering, Nanjing University of Aeronautics and Astronautics, China.
Lu Jin, born in 1994, is currently a master candidate at College of Mechanical and Electrical Engineering, Nanjing University of Aeronautics and Astronautics, China.

Jixing Du, born in 1995, is a master candidate at College of Mechanical and Electrical Engineering, Nanjing University of Aeronautics and Astronautics, China.

Liang Li, born in 1959, is currently a professor at College of Mechanical and Electrical Engineering, Nanjing University of Aeronautics and Astronautics, China.

Wei Yang, born in 1980, is an engineer at Shenyang Aircraft Corporation, China.

\section{Funding}

Supported by National Natural Science Foundation of China (Grant No. 51405226).

\section{Competing Interests}

The authors declare no competing financial interests.

\section{Author Details}

1 Nanjing University of Aeronautics and Astronautics, Nanjing 210016, China.

${ }^{2}$ Shenyang Aircraft Corporation, Shenyang 110034, China.

Received: 15 August 2019 Revised: 5 March 2020 Accepted: 23 April 2020 Published online: 11 May 2020

\section{References}

[1] P Rambabu, N E Prasad, V V Kutumbarao, et al. Aluminum alloys for aerospace applications. In: Aerospace Materials and Material Technologies, Springer Singapore, 2017

[2] X M Zhang, Y L Deng, Y Zhang. Development of high strength aluminum alloys and processing techniques for the materials. Acta Metallurgica Sinica, 2015, 51(3): 257-271.

[3] P Lequeu, P Lassince, TWarner, et al. Engineering for the future: weight saving and cost reduction initiatives. Aircraft Engineering \& Aerospace Technology, 2013, 73(2): 147-159.

[4] A Heinz, A Haszler, C Keidel, et al. Recent development in aluminum alloys for aerospace applications. Materials Science \& Engineering A, 2000, 280(1): 102-107.

[5] W M Sim. Challenges of residual stress and part distortion in the civil airframe industry. International Journal of Microstructure \& Materials Properties, 2010, 5(4/5): 446

[6] Z J Wang, WY Chen, Y D Zhang, et al. Study on the machining distortion of thin-walled part caused by redistribution of residual stress. Chinese Journal of Aeronautics, 2005, 18(2): 175-179.

[7] J Sun. Study on machining distortion of unitization airframe due to residual stress. Journal of Mechanical Engineering, 2005, 41(2): 117-122. (in Chinese)

[8] YWei. Numerical simulation of the machining distortion of aircraft aluminum part caused by redistribution of residual stress. Advanced Materials Research, 2010, 142: 122-125.

[9] S Nervi, A Barna. Szabó, et al. Prediction of distortion of airframe components made from aluminum plates. AIAA Journal, 2009, 47(7): 1635-1641.

[10] J S Wang, C C Hsieh, C M Lin, et al. Texture evolution and residual stress relaxation in a cold-rolled Al-Mg-Si-Cu alloy using vibratory stress relief technique. Metallurgical \& Materials Transactions A, 2013, 44(2): 806-818.

[11] J Song, Y Zhang. Effect of vibratory stress relief on fatigue life of aluminum alloy 7075-T651. Advances in Mechanical Engineering, 2016, 8(6), https://doi.org/10.1177/1687814016654379.

[12] K Koenig, G Muller, U Grahlmann. Some remarks on the acoustic fatigue of aluminum skin-stringer structures with either integrally milled or rivetted edge reinforcements. Aerospace Science \& Technology, 1998, 2(1): 27-36.

[13] O S Zaroog, A Ali, B B Sahari, et al. Modeling of residual stress relaxation of fatigue in 2024-T351 aluminium alloy. International Journal of Fatigue, 2011, 33(2): 279-285.

[14] J S Wang, C C Hsieh, C M Lin, et al. The effect of residual stress relaxation by the vibratory stress relief technique on the textures of grains in AA 
6061 aluminum alloy. Materials Science and Engineering: A, 2014, 605 98-107.

[15] B J Kim, Y R Son, J O Yun, et al. Residual stress relief and redistribution of welded metals by vibratory stress relaxation. Materials Science Forum, 2008, 580-582: 419-423.

[16] X D Liu, X H Tao, Z Q Han. Application of vibratory stress relief in relaxation of residual stress for expandable corrugated liners. Journal of Vibration \& Shock, 2015, 34(4): 171-174.

[17] LP Ru, J Moverare, P Avdovic, et al. Influence of vibration and heat treat ment on residual stress of a machined $12 \% \mathrm{Cr}$-steel. Advanced Materials Research, 2014, 996: 609-614.

[18] S Kodama. The behavior of residual stress during fatigue stress cycles. Proceedings of the International Conference on Mechanical Behavior of Metals II, Kyoto: Society of Material Science, 1972, 2: 111-118.

[19] S Han, T Lee, B Shin. Residual stress relaxation of welded steel components under cyclic load. Steel Research, 2002, 73(9): 414-420.

[20] W Z Zhuang, G R Halford. Investigation of residual stress relaxation under cyclic load. International Journal of Fatigue, 2001, 23(1): 31-37.

[21] J S Robinson, D A Tanner, C E Truman, et al. Measurement and prediction of machining induced redistribution of residual stress in the aluminium alloy 744. Experimental Mechanics, 2011, 51(6): 981-993.

[22] Y W Liu. Numerical simulation of the machining distortion of aircraft aluminum part caused by redistribution of residual stress. Advanced Materials Research, 2011, 142: 122-125.

[23] V Schulze, P Arrazola, F Zanger, et al. Simulation of distortion due to machining of thin-walled components. Procedia CIRP, 2013, 8: 45-50.

[24] Y H Hu, Y X Wu, L Chen. Residual stress relaxation of shot peened 7075 aluminum alloy under cyclic load. Materials Research \& Application, 2010, 004(003): 174-179. (in Chinese)
[25] L Meng, M Atli, N He. Measurement of equivalent residual stresses generated by milling and corresponding deformation prediction. Precision Engineering, 2017, https://doi.org/10.1016/j.precisioneng.2017.05.003.

[26] X Huang, J Sun, J Li. Effect of initial residual stress and machining-induced residual stress on the deformation of aluminum alloy plate. Strojniski Vestnik, 2015, 61(2): 131-137.

[27] S Masoudi, S Amini, E Saeidi, et al. Effect of machining-induced residual stress on the distortion of thin-walled parts. International Journal of Advanced Manufacturing Technology, 2015, 76(1-4): 597-608.

[28] ASTM D4728-06 Standard Test Method for Random Vibration Testing of Shipping Containers, 2012.

[29] M R Hill, M D Olson. Repeatability of the contour method for residual stress measurement. Experimental Mechanics, 2014, 54(7): 1269-1277.

[30] M R James. Relaxation of residual stress an overview. Residual Stresses, 1987: 349-365.

[31] $Y H H u, Y X W u, G Y W a n g$, et al. Surface yield strength gradient versus residual stress relaxation of 7075 aluminum alloy. Advanced Materials Research, 2010: 160-162, 241-246.

[32] N Aleksandrova. Application of Mises yield criterion to rotating solid disk problem. International Journal of Engineering Science, 2012, 51: 333-337.

[33] Y Z Chen. A numerical procedure for evaluating the plastic limit load of a circular plate using Mises yield criterion. Computers \& Structures, 1986, 24(5): 821-822

[34] A N Eraslan. Von Mises yield criterion and nonlinearly hardening variable thickness rotating annular disks with rigid inclusion. Mechanics Research Communications, 2002, 29(5): 339-350.

\section{Submit your manuscript to a SpringerOpen ${ }^{\odot}$ journal and benefit from:}

- Convenient online submission

- Rigorous peer review

- Open access: articles freely available online

- High visibility within the field

- Retaining the copyright to your article

Submit your next manuscript at springeropen.com 